\title{
Intraneuronal Compartments of the Amyloid Precursor Protein
}

\author{
Adriana Ferreira, Alfredo Caceres, and Kenneth S. Kosik \\ Harvard Medical School and Center for Neurologic Diseases, Department of Medicine (Division of Neurology), Brigham \\ and Women's Hospital, Boston, Massachusetts 02115
}

\begin{abstract}
The amyloid precursor protein (APP) is the parent molecule from which $\beta$-amyloid protein is cleaved and deposits as amyloid fibrils in the senile plaques of Alzheimer's disease. Its primary structure resembles a receptor; however, no ligand has been identified. In growing hippocampal neurons APP is localized to growth cones. APP immunoreactivity was highly enriched in the axons of mature cultured neurons, where it appears as a specialization of the axonal membrane. Its anterograde translocation occurs via a kinesinbased motor. Following cytosolic acidification, APP colocalizes with late endosomes that get redistributed from the neuronal cell body to the processes. APP colocalizes in cultured hippocampal neurons to clathrin-immunoreactive clusters of vesicular-like structures. The finding lends additional credence to the possibility that APP could function as a receptor.
\end{abstract}

[Key words: hippocampal neurons, clathrin, endosomes, kinesin, antisense, endocytosis]

Cells must target proteins to specific classes of organelles in order to segregate molecules within discrete cellular locales. Polarized cells have the added task of directing organelles correctly to large cellular regions such as the apical versus the basal surface in epithelial cells, or the axon versus the dendrite in neurons. Understanding the systems by which proteins move to the membrane and get secreted, as well as their intracellular membrane compartments, represents a crucial phase in ascertaining a normal role for the amyloid precursor protein (APP). APP was discovered as the parent molecule of a much smaller fragment that deposits in the senile plaques and in many cerebral blood vessels in Alzheimer's disease (for review, see Kosik, 1992). Therefore, the processing of this molecule is important because a proteolytic product, designated $\beta-\mathrm{AP}$, forms the amyloid fibrils.

The precise intraneuronal localization of APP has not been established. Even less is known about its neuronal localization during neuronal development. The first clue regarding localization came from the primary structure of APP, which resembles a glycosylated cell surface receptor (Kang et al., 1987). Isoforms that are both $\mathrm{N}$ - and O-glycosylated have been described (Weidemann et al., 1989), and cleaved forms of the precursor are secreted into the media of cell cultures. One of these forms is

\footnotetext{
Received Nov. 13, 1992; revised Feb. 3, 1993; accepted Feb. 8, 1993.

This work was supported by NIH Grant AG06601 and a Zenith fellowship from the Alzheimer's Association to K.S.K.

Correspondence should be addressed to Kenneth S. Kosik, M.D., Center for Neurologic Diseases, Brigham and Women's Hospital, 221 Longwood Avenue (LMRC), Boston, MA 02115.

Copyright $\odot 1993$ Society for Neuroscience $0270-6474 / 93 / 133112-12 \$ 05.00 / 0$
}

the serine protease inhibitor protease nexin II (Van Nostrand and Cunningham, 1987). In neuronal cells little is known about how APP is targeted to the membrane other than the report that APP moves in the rapid phase of axonal transport (Koo et al., 1990), suggesting that after its glycosylation, APP associates with an anterogradely moving organelle in the trans-Golgi compartment. In addition to its secretion, APP is associated with the endosomal/lysosomal compartment (Estus et al., 1992; Golde et al., 1992; Haass et al., 1992). An NPXY sequence located in the cytoplasmic tail of APP is presumably involved in this targeting.

The normal APP gene product is expressed in many different tissues and cell types at quite variable levels. It is most abundant in neurons as detected by in situ hybridization (Bahmanyar et al., 1988; Bendotti et al., 1988; Cohen et al., 1988; Shivers et al., 1988). Among brain regions the highest levels are in the olfactory areas, cerebral cortex, hippocampus, amygdala, and cerebellum (Shivers et al., 1988). The localization of the protein immunocytochemically is also in general, concordant with a predominantly neuronal localization (Card et al., 1988; Shivers et al., 1988). In these published micrographs there is a significant degree of variation among neuronal populations in the intensity of APP staining even within an anatomically restricted area. Higher-resolution electron microscopic studies describe colocalization of APP with synaptophysin at synaptic sites and with vesicular elements in human and rat neurons (Schubert et al., 1991). In some cell types of the adenohypophysis APP antibodies labeled some secretory granules (Catterucia et al., 1990). These patterns were reported to differ from that obtained with an antiserum against lysosomes (Shivers et al., 1988).

The localization of APP in neurons must be placed in the context of the known intracellular pathways by which membrane-bound organelles move through cells. Little is known about the membrane trafficking events in neurons, which due to their highly polar structures, and long processes present unique problems in the routing of organelles. The absence of protein synthesis in the axon requires the delivery of proteins over long distances rather than local synthesis. It has been proposed that epithelial cells and neurons utilize similar mechanisms to sort certain glycoproteins (Dotti and Simons, 1990). In epithelial Madin-Darby canine kidney (MDCK) cells, newly synthesized proteins targeted for either the apical or the basolateral membranes travel together in the trans-Golgi network, from where apical proteins are transcytosed to the apical membrane. (Griffiths and Simons, 1986; Hughson et al., 1988). Using the viral glycoprotein products of the vesicular stomatitis virus, which in MDCK cells is a basolateral protein, there was localization to dendrites. In contrast, the hemagglutinin protein of the influenza fowl plague virus, which in MDCK cells is apically sort- 
ed, was preferentially targeted to the axon (Dotti and Simons, 1990).

Dissociated rat hippocampal neurons are an intensively studied culture system that can sometimes reveal the cytological localization of a protein whose localization in tissue sections is obscured by the complex interrelationships among cells in neural tissue. We have localized APP to the growing tips of neurites in hippocampal neurons in culturc. During maturation in culture we were able to inhibit the transport of APP to the tips of processes in the presence of kinesin antisense oligonucleotides. Here we have presented evidence for the association of APP with certain classes of membrane-bound organelles in neurons, particularly clusters of clathrin-coated vesicles and late endosomes. The common use of this internalization pathway by receptors provides indirect evidence that APP may serve as a receptor for which a ligand has not yet been identified.

\section{Materials and Methods}

Cultures. Cultures were prepared from the hippocampi of embryonic day 18 rats as previously described (Bartlett and Banker, 1984). In brief, cells from the dissected hippocampi were dissociated by trypsinization $\left(0.25 \%\right.$ for $15 \mathrm{~min}$ at $\left.37^{\circ} \mathrm{C}\right)$ followed by trituration with a fire-polished Pasteur pipette. For immunofluorescence the cells were plated at a density of 100,000 cells $/ 60 \mathrm{~mm}$ Petri dish on glass coverslips coated with poly-L-lysine $(1 \mathrm{mg} / \mathrm{ml})$ in minimum essential medium (MEM) with $10 \%$ horse serum. In antisense experiments, cells were plated onto 12 mm-diameter coverslips in $35 \mathrm{~mm}$ dishes. After 2-4 hr the medium was changed to $1 \mathrm{ml}$ of MEM with $\mathrm{N} 2$ supplements (Bottenstein and Sato, 1979), ovalbumin $(0.1 \%)$, and pyruvate $(0.01 \mathrm{mg} / \mathrm{ml})$ that had been conditioned in cultures of astroglial cells for $24 \mathrm{hr}$ and the cells were left faceup. All cultures used in immunolocalization studies were cocultured with astroglia.

Antisense oligonucleotides. The kinesin heavy chain was inhibited with antisense oligonucleotides as described previously (Fcrreira et al., 1992). The antisense oligonucleotide $-11+14$ rkin used in these experiments consists of the sequence GCCGGGTCCGCCATCTTTCTG GCAG and is the inverse complement of the rat nucleotides -11 to +14 . The oligonucleotides were synthesized on an Applied Biosystems $380 \mathrm{~B}$ synthesizer, purified over an NAP5 column (Pharmacia), ethanol precipitated, and taken up in media. The administration of the oligonucleotide was as follows. At $2-4 \mathrm{hr}$ after plating, when the cells were transferred to serum-free glia-conditioned medium, the oligonucleotide was added at $50 \mu \mathrm{M}$. The medium was supplemented with $25 \mu \mathrm{M}$ additional oligonucleotide every $12 \mathrm{hr}$ from the time of plating for either 24 or $48 \mathrm{hr}$. Controls were treated with the same concentration and dosage schedule of the corresponding sense-strand oligonucleotide.

Acidification media and Lucifer yellow labeling. The procedure for the $\mathrm{pH}$-induced redistribution of the late endosomes is as described by Heuser (1989). The buffers used were Ringer's solution (155 mM NaCl, $5 \mathrm{~mm} \mathrm{KCl}, 2 \mathrm{~mm} \mathrm{CaCl}, 1 \mathrm{~mm} \mathrm{MgCl}_{2}, 2 \mathrm{~mm} \mathrm{NaH}_{2} \mathrm{PO}_{4}, 10 \mathrm{~mm}$ HEPES pH $7.20,10 \mathrm{~mm}$ glucose, $0.5 \mathrm{mg} / \mathrm{ml} \mathrm{BSA}$ ) and acetate Ringer's that involved the following changes: $80 \mathrm{~mm} \mathrm{NaCl}, 70 \mathrm{~mm}$ Na-acetate, 10 mM HEPES, $\mathrm{pH}$ 6.90. This more acidic $\mathrm{pH}$ was shown to produce a redistribution of the late endosomes in neurons (Parton et al., 1991). Cells were incubated in Lucifer yellow (dilithium salt, Sigma Chemical Co.) at a concentration of $10 \mathrm{mg} / \mathrm{ml}$ in glia-conditioned medium for 30 min at $37^{\circ} \mathrm{C}$, followed by a $30 \mathrm{~min}$ chase in medium. After the chase cells were incubated in acetate Ringer's pH 6.90 for 15 min or in Ringer's $\mathrm{pH} 7.2$ and then fixed for immunostaining and fluorescence microscopy.

Immunodetection. For immunostaining the cultures were fixed for 20 min with warm $4 \%$ formaldehyde in PBS containing $0.12 \mathrm{~m}$ sucrose, permeabilized in $0.3 \%$ Triton X-100 for $5 \mathrm{~min}$ at room temperature, and rinsed in PBS. Cultures were incubated with 10\% BSA for $1 \mathrm{hr}$ at $37^{\circ} \mathrm{C}$, and then exposed to primary antibody or antibodies (diluted in $1 \%$ BSA/PBS) overnight at $4^{\circ} \mathrm{C}$. The antibodies used were $\mathrm{C} 7$ and $\mathrm{C} 6$, polyclonal antibodies raised against the carboxy terminus of APP (peptides 676-695), diluted 1:50 (Selkoe et al., 1988; Hass et al., 1991), gifts from Dennis Selkoe (Harvard Medical School, Boston, MA); a polyclonal antibody against the clathrin heavy chain (Sigma Chemical Co.), used at a dilution of 1:40; X16, a monoclonal antibody against the higher-molecular-weight clathrin light chain (Brodsky, 1985: Wong et al., 1990), used at dilution of $20 \mu \mathrm{g} / \mathrm{ml}$, gift of Francis Brodsky (Univ. of Alabama, Birmingham, AL); AP 14, a monoclonal antibody against MAP2 from Lester Binder (UCSF, San Francisco, CA) and used at a dilution of 1:100; DM1B, a monoclonal antibody against $\beta$-tubulin (Boehringer), at a dilution of 1:1000; and a monoclonal antibody against synaptophysin (Boehringer), used at a dilution of 1:20. The specificity of $\mathrm{C} 7$ was confirmed by an adsorption experiment in which staining was abolished following incubation with an excess of the peptide immunogen.

The secondary antibodies used were goat anti-mouse, goat anti-rabbit, or swine anti-goat $\operatorname{lgG}$ conjugated to fluorescein isothiocyanate or rhodamine at a dilution of 1:100 (Boehringer). For double-labeling experiments two antibodies wcre incubated with the cells together in all cases except for the clathrin antibody. Since the clathrin antibody was made in goat, it required sequential immunolabeling.

\section{Results}

\section{APP localization during maturation of cultured hippocampal} neurons

Antibodies directed against the carboxy-terminal region of APP label a distinctive pattern in hippocampal neurons. Shortly after plating, hippocampal neurons extend a lamellipodial veil (stage I) that later consolidates into several minor neurites (stage II). At stage II APP antibodies intensely labeled the growing tips of minor neurites as well as the cell body (Fig. $1 B$ ). Tubulin is relatively excluded from this region (Fig. $1 A$ ) as expected in the growth cone. Within the first $24 \mathrm{hr}$ after plating hippocampal ncurons selectively elongate one minor neurite that becomes the axon (stage III). Cells undergoing axonal elongation continue to demonstratc APP immunoreactivity at the tips of the elongating axon and at the tips of the minor neurites (Fig. $1 C, D$ ). Higherpower views revealed that APP was present in the most distal portion of the growth cone, where filopodia undergo rapid extension and retraction (Fig. $l F$ ). This region of the growth cone contains bundles of actin filaments within the filopodial spikes and is relatively devoid of microtubules (Fig. $1 E$ ). Growth cones have very diverse morphologies (Fig. $1 E-H$ ); however, even in less well spread growth cones the APP immunoreactivity is localized to the tip (Fig. $1 / I$ ). At approximately $72 \mathrm{hr}$ the remaining minor neurites of the hippocampal neurons undergo dendritic differentiation (stage IV). APP immunoreactivity is present at the tips of elongating dendrites as visualized with two different APP antibodies (Fig. $2 A, B$ ). Within the growth cones of neurites APP immunoreactivity was lost after Triton extraction, suggesting that its localization in the growth was not associated with the cytoskeleton. Rare non-neural cells in the culture were only faintly stained.

Because the localization of APP correlated well with the growing tip of neurites, we sought to determine if the distribution of APP changed when neurons developed synaptic contacts. After 12-15 d in culture the site of APP immunoreactivity shifted from the growing tips to the shafts of the processes. Two patterns of staining were apparent. One was a diffuse staining along the entire process, a pattern observed in a subset of processes (Fig. $3 B)$. The second pattern was a punctate stain deposited in an irregular array along some processes (Fig. $3 D$ ). This sccond pattern was seen in many of the processes, including those with the diffuse stain, and more commonly in those without diffuse staining. The shift to an axonal pattern began at approximately 12-15 d after plating. Comparison with a tubulin antibody was used to visualize the total population of processes (Fig. $3 A, C$ ).

The identity of APP-labeled processes was ascertained by double labeling with the somatodendritic marker protein MAP2 (microtubule-associated protein 2). APP was confined to processes that were not labeled by the MAP2 antibody (Fig. 4), suggesting an axonal localization of APP. Axons often grow 

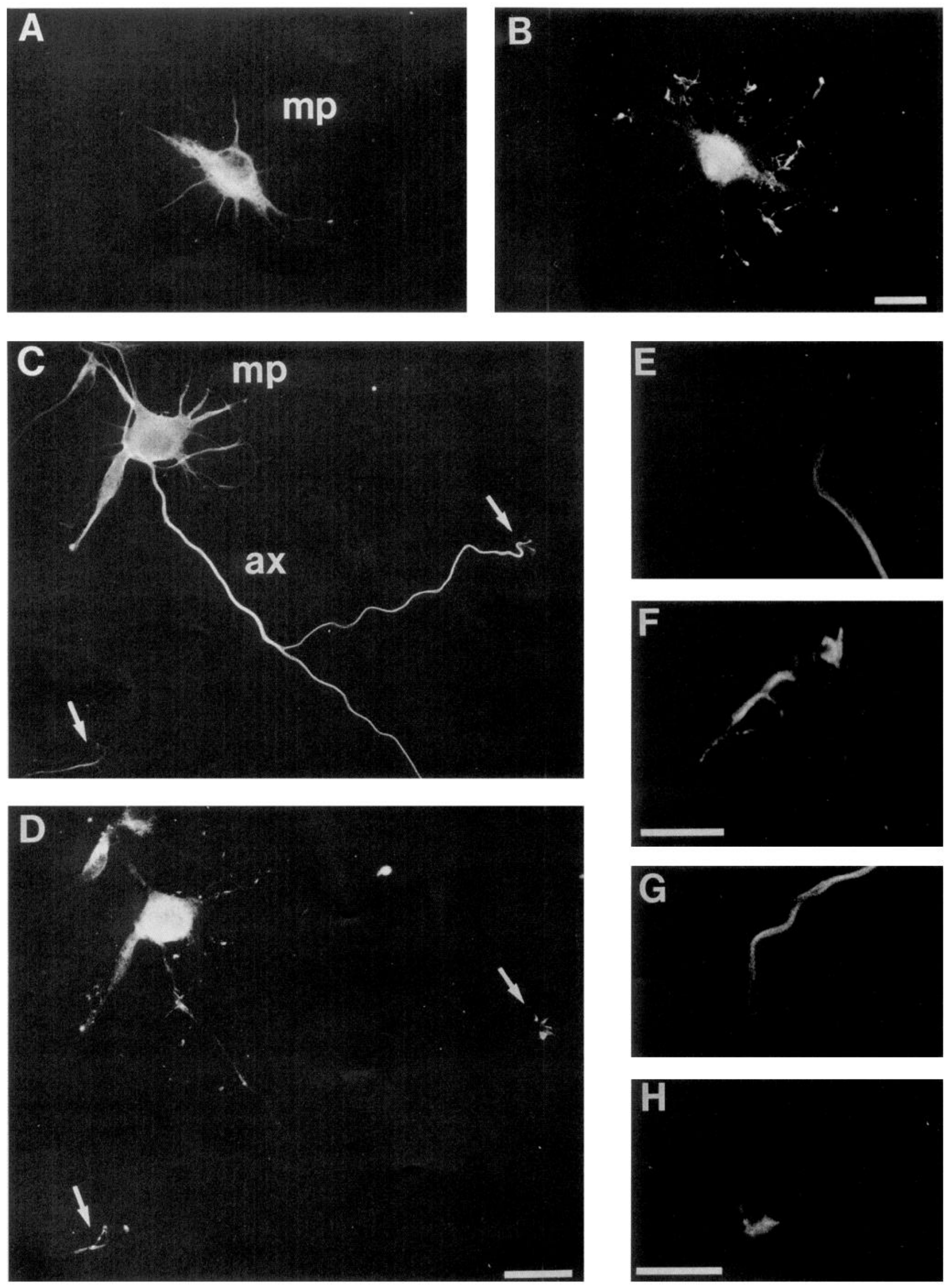

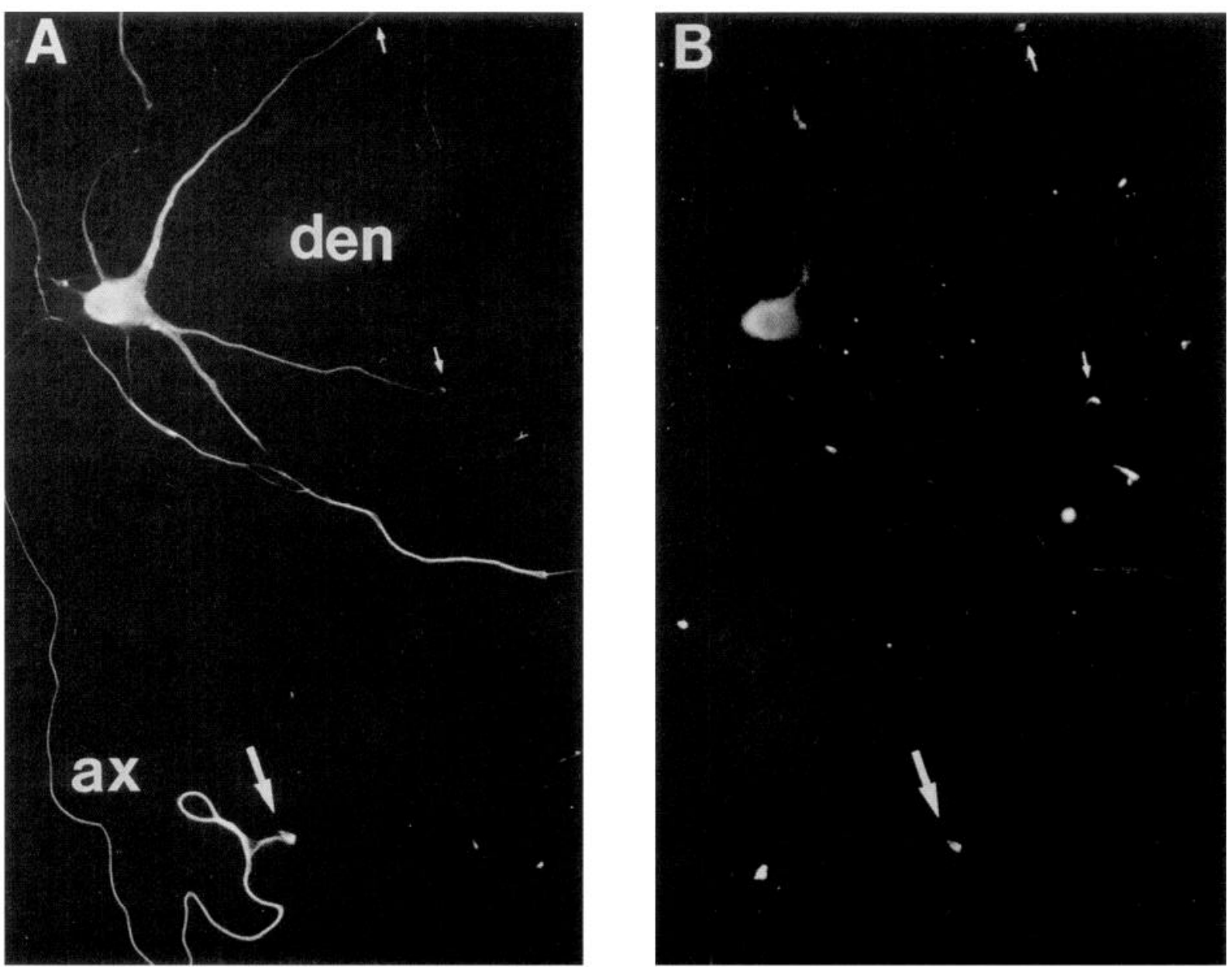

Figure 2. Stage IV hippocampal neurons with APP immunoreactivity in dendritic (den, small arrows) as well as axonal (ax, large arrows) growth cones. $A$ and $B$ represent the same cells double labeled with a tubulin antibody $(A)$ and the APP antibody, C7 $(B)$. Scale bar, $20 \mu \mathrm{m}$.

alongside the dendrite, and indeed, APP-labeled axons were often seen as thin structures that followed the course of the thicker dendrite labeled with MAP2 antibody (Fig. 4A,B). Dendrites labeled with APP antibodies at background levels or just slightly above background levels. Further evidence for the axonal localization was provided by low-density cultures. By 30 d hippocampal neurons elaborate a dense web of fine-caliber axons, often fasciculating with other processes, that extend far from the cell body. In contrast, dendrites are thickened, tapering processes that lie closer to the cell body. In fields sufficiently far from cell bodies where the dendrites were not present, MAP2 did not label any of the processes, whereas APP did (Fig. 4C,D).

\section{APP colocalizes with clathrin-stained clusters of vesicular structures}

The punctate appearance of APP in the axons of hippocampal neurons suggested an association with membrane-bound organelles or clusters of membrane-bound organelles. Following extraction with $0.5 \%$ Triton X-100 all APP immunoreactivity was lost, but tubulin immunoreactivity was retained (data not shown). This finding implies that detergent-induced dissolution of the membrane released APP. The organelles labeled by APP antibodies were tentatively identified as clathrin-coated vesicles by precise colocalization with antibodies directed against clathrin heavy chain (Fig. 5). As described previously (Bloom et al., 1980), clathrin antibodies label large clusters of membrane-bound organelles in neurons. Within the regions of punctate label it was possible occasionally to observe clusters of dots (Fig. $5 F$ ). A subset of the axonal processes in culture labeled in this punctate pattern with both antibodies, suggesting that a subset of axons exists that is undergoing active internalization of APP. Clathrin antibody also labeled the growth cones of neurons in culture and densely labeled the cell body. As described above these sites of label were also detected with antibodies to APP. Clathrin labeling was observed in dendrites, a site from which APP was excluded.

The APP punctate stain often appeared positioned at points of contact between neuronal processes. It was therefore possible

Figure 1. Localization of APP to growth cones in developing hippocampal neurons in culture. $A$ and $B$, Double-labeled stage II neuron with minor processes $(\mathrm{mp})$ stained by a tubulin antibody $(A)$ and by the APP antibody C7 $(B)$. $C$ and $D$, Double-labeled stage III neuron in which one process has differentiated into an axon $(a x)$ stained by a tubulin antibody $(C)$ and by the APP antibody C7 $(D)$. The arrows point to axonal growth cones. $E-H$ are higher-power views of staining in growth cones where the staining is confined to the most distal region of the tip. $E$ and $G$ are stained with the tubulin antibody, and $F$ and $H$ are stained with $C 7$. Scale bars, $20 \mu \mathrm{m}$. 

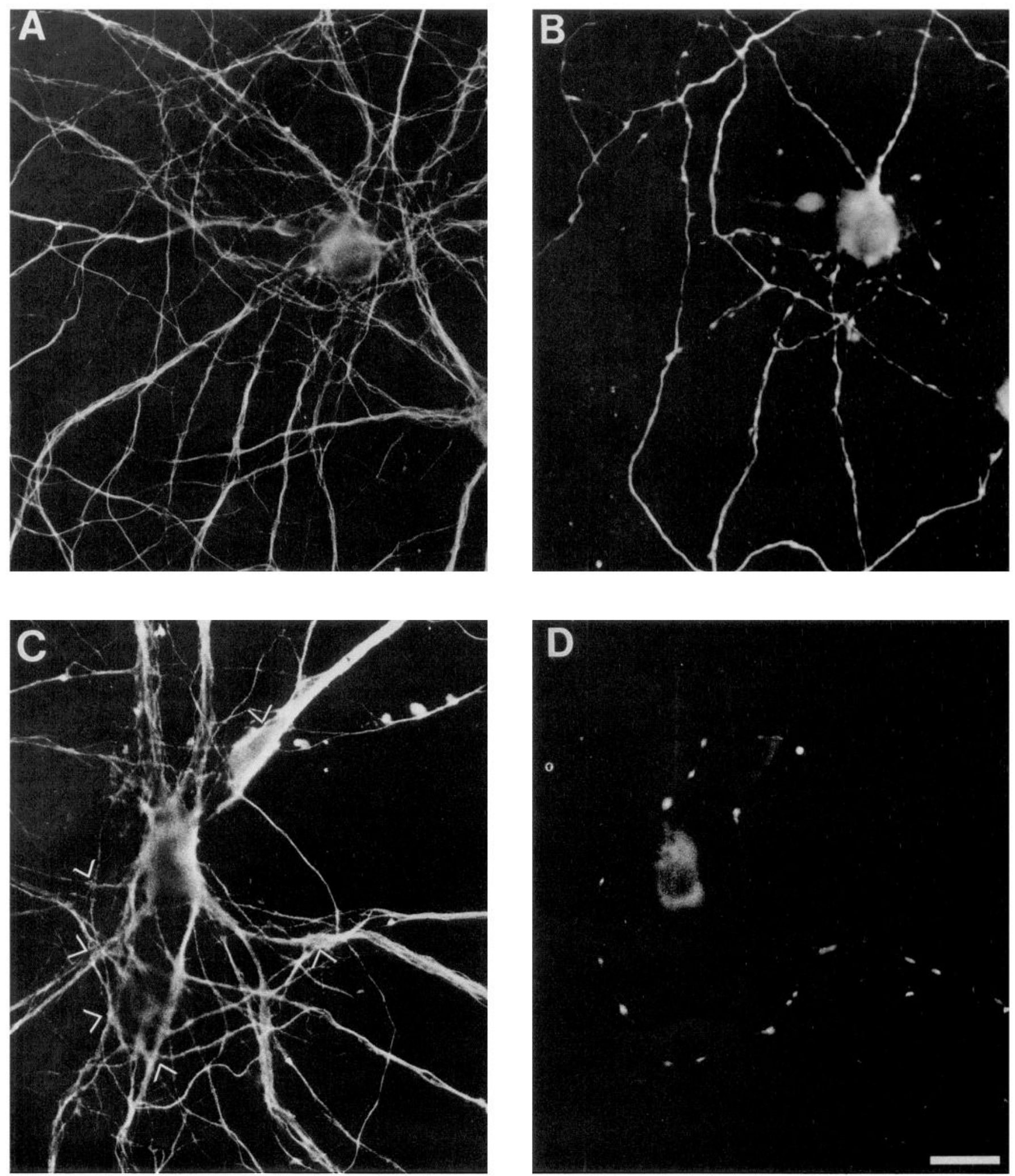

Figure 3. APP immunoreactivity in mature [ $30 \mathrm{~d}$ in vitro (DIV)] hippocampal neurons: double labeling ( $A$ and $B$ are the same field, and $C$ and $D$ are the same field) with tubulin antibody $(A, C)$ and with the APP antibody C7 $(B, D)$. All of the processes are labeled in $A$ and $C$, whereas a subset are labeled in $B$ and $D$. APP-containing processes label in two patterns: diffusely $(B)$ and punctate $(D)$. The subset of processes with APP have the appearance of axons in that they are of relatively fine and uniform in caliber. Arrowheads indicate sites of contact between processes. Scale bar, $20 \mu \mathrm{m}$. 

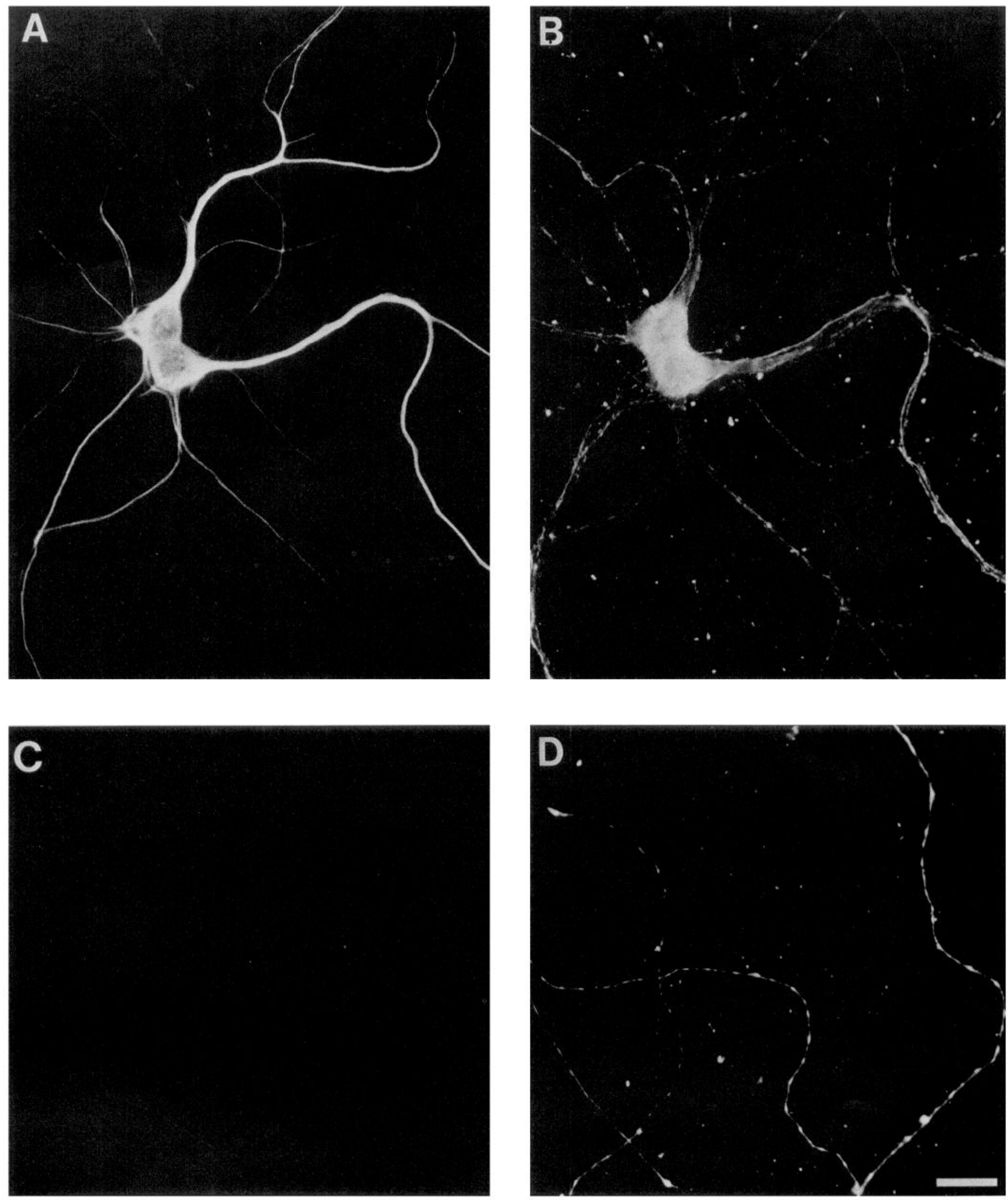

Figure 4. Axonal localization of APP in mature (30 DIV) hippocampal neurons: double labeling with MAP2 antibody AP14 ( $A, C)$ and the APP antibody $C 7(B, D) . A$ and $B$ are the same field, and $C$ and $D$ are the same field. MAP2 labels the dendrites seen as thick, tapering processes $(A)$ that are shorter than axons and therefore not observed in fields more distant from cell bodies $(C)$. C7 labels fine-caliber processes that as is characteristic of axons, may run along the dendrite, and in sparsely plated cultures, extend farther from the cell bodies $(D)$. Scale bar, $20 \mu \mathrm{m}$. 

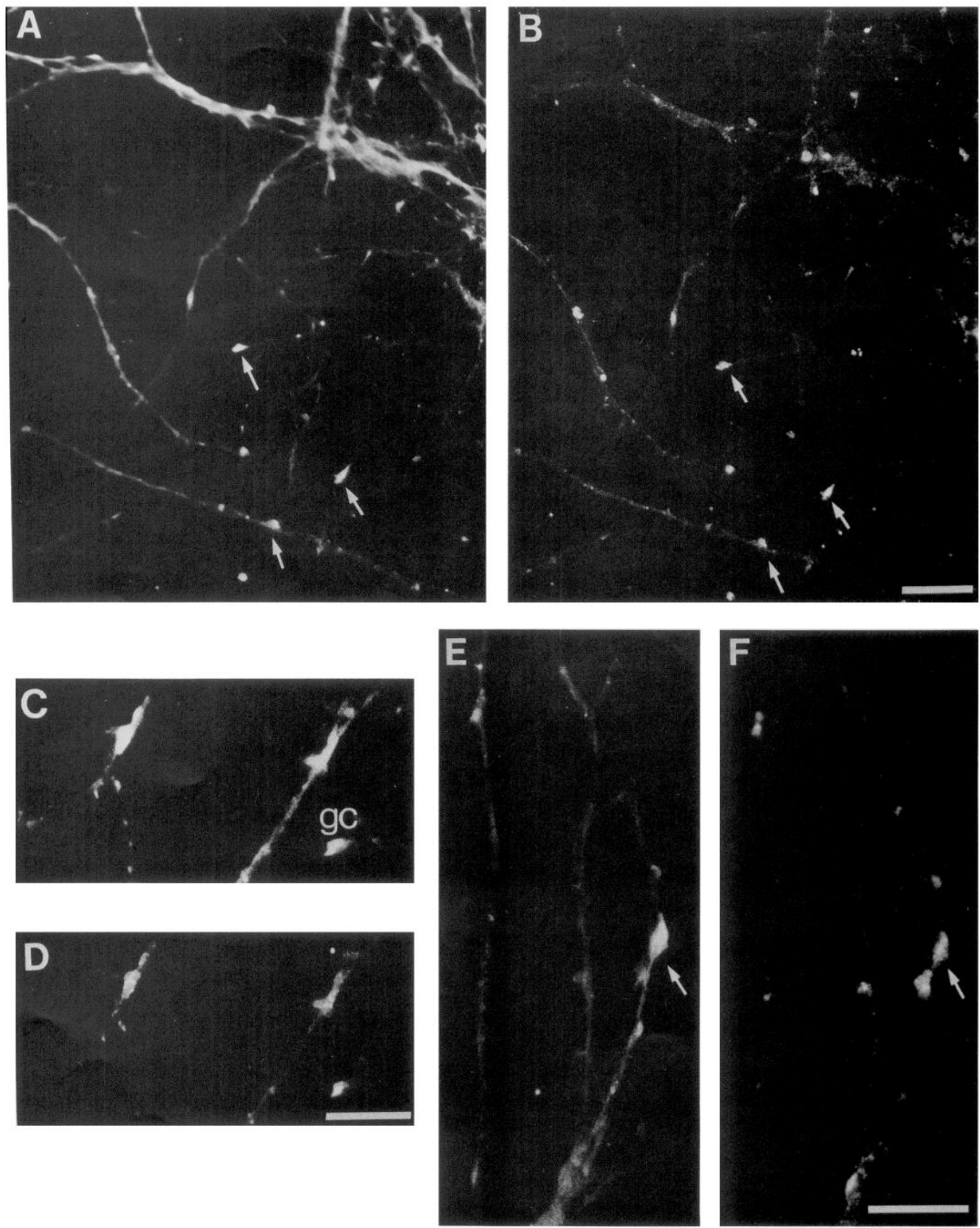

Figure 5. Clathrin heavy-chain staining colocalizes with APP in hippocampal neurons at 30 DIV. The patterns of colocalization are shown in the double-labeled pairs $A / B, C / D$, and $E / F$, which represent the same field stained with the APP antibody $C 7(A, C, E)$ and clathrin heavy-chain antibody $(B, D, F)$. Arrows indicate some sites of colocalization, in which clathrin-coated vesicles have clustered. More discrete punctate staining within the clusters can be observed in $F($ arrow). A growth cone $(g c)$ is also labeled by both antibodies. Scale bars, $20 \mu \mathrm{m}$. 

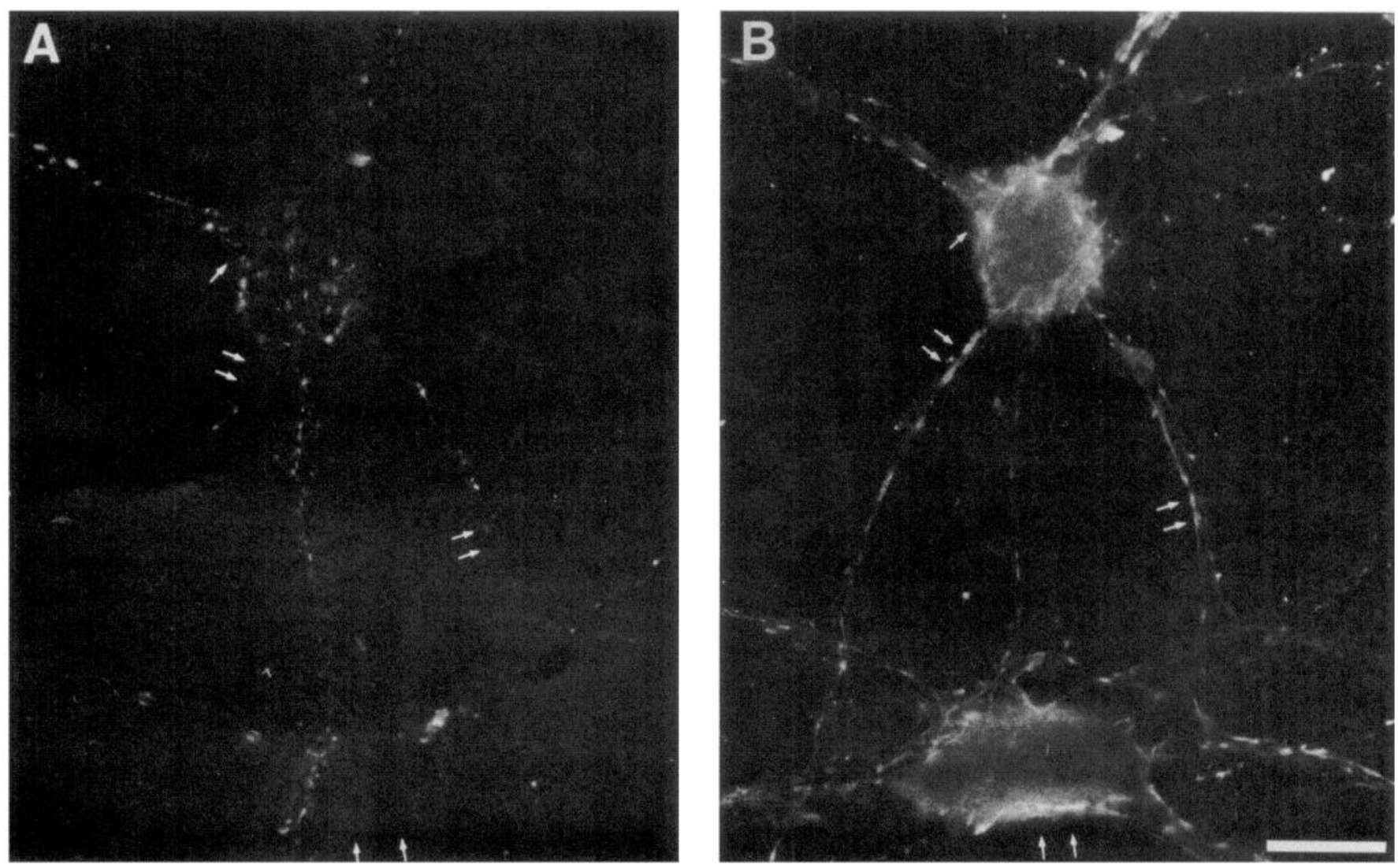

Figure 6. Double labeling of 30 DIV hippocampal neurons with a synaptophysin antibody $(A)$ and antibody C7 against APP $(B)$. The antibodies do not colocalize as seen best at the sites indicated with arrows. Scale bar, $20 \mu \mathrm{m}$.

that these sites represented points of synaptic contact, and indeed, clathrin-coated vesicles have been described in the region of synapses (Wong et al., 1990). However, APP did not colocalize with synaptophysin antibodies (Fig. $6 A, B$ ). The punctate reaction product from the two antibodies were nonoverlapping, suggesting that APP localization in axons did not correspond to synaptic sites. Reports concerning processing of APP in a lysosomal compartment prompted us to stain the cells with a cathepsin D antibody. Staining with this antibody was confined to the region of the cell body (data not shown). It therefore seemed unlikely that very much of the APP in neuronal processes is in lysosomes.

\section{Following internalization APP moves to an endosomal compartment}

Clathrin-coated vesicles move their contents to an endosomal compartment from which sorting occurs to a variety of destinations. One possible route is the passage to late endosomes and lysosomes where degradation occurs. The experiment that provided evidence for the presence of APP in late endosomes was the $\mathrm{pH}$-induced redistribution of APP-containing organelles. The neuronal culture was incubated in acetate Ringer's at $\mathrm{pH} 6.90$ for $15 \mathrm{~min}$ before fixation and immunolabeling. This procedure drives late endosomal constituents out into neuronal processes (Parton et al., 1991). Following the $\mathrm{pH}$ shift, a punctate pattern of APP staining was present in all of the axons, in contrast to the subpopulation labeled in cultures without the $\mathrm{pH}$ adjustment, and the staining appeared considerably more intense (Fig. 7). The $\mathrm{pH}$-induced redistribution respected the ax- onal compartmentation of the APP-labeled organelles since the procedure failed to drive these organelles into the dendrites.

To determine the efficacy of the acidification procedure in 30-d-old hippocampal neurons, control cells were incubated in Lucifer yellow for $30 \mathrm{~min}$ followed by a chase for $30 \mathrm{~min}$ in marker-free medium. During this time Lucifer yellow is taken up by fluid-phase endocytosis throughout the cell and carried back to the neuronal cell body destined for late endosomes. The cells were then washed in Ringer's, pH 7.20, and reincubated in acetate Ringer's, $\mathrm{pH} 6.90$ or 7.20 , for a further $15 \mathrm{~min}$ before fixation and immunostaining with APP antibodies. Following acidification Lucifer yellow-containing organelles, appeared in the processes and often colocalized with APP-containing organelles (Fig. $7 C, D$ ). This finding suggests that one of the organelles with which APP is associated in the neuronal cell body is the late endosome. This experiment also served to determine whether the shift of APP-containing organelles to the axon was a feature only of these organelles transporting APP, or whether all late endosomes segregated to the axon under the conditions of reduced cytosolic $\mathrm{pH}$. Following the $\mathrm{pH}$ shift Lucifer yellowlabeled late endosomes were confined to the axon (Fig. $7 E, F$ ). As expected, cultures in which the final incubation was at $\mathrm{pH}$ 7.2 did not show Lucifer yellow labeling in any of the processes. These results suggested that shifting the $\mathrm{pH}$ polarized the endosomes to an axonal compartment.

\section{Use of kinesin antisense oligonucleotides}

To assess the anterograde movement of APP in the cultured neurons, we utilized kinesin heavy-chain antisense oligonucleo- 

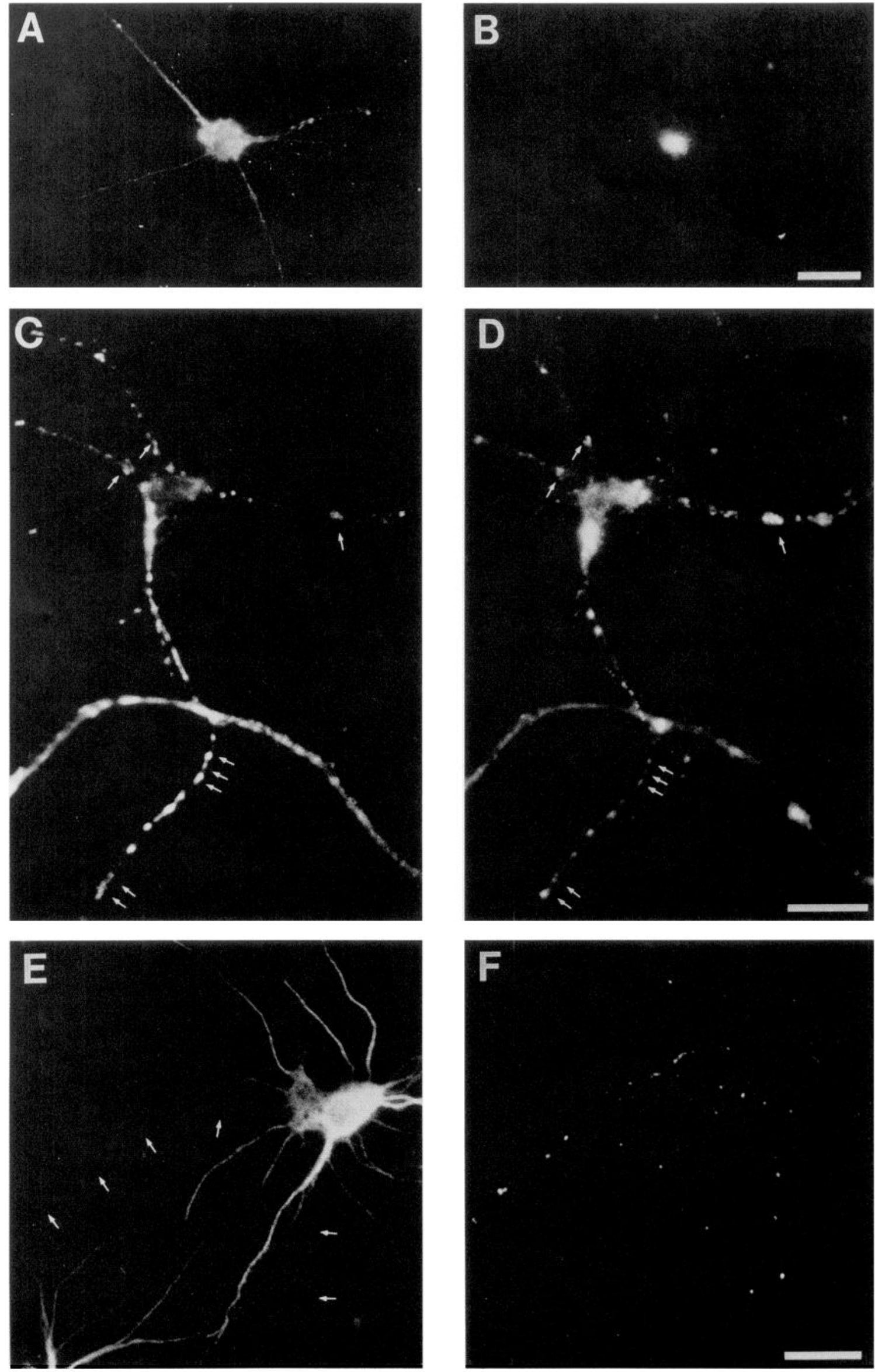

F 

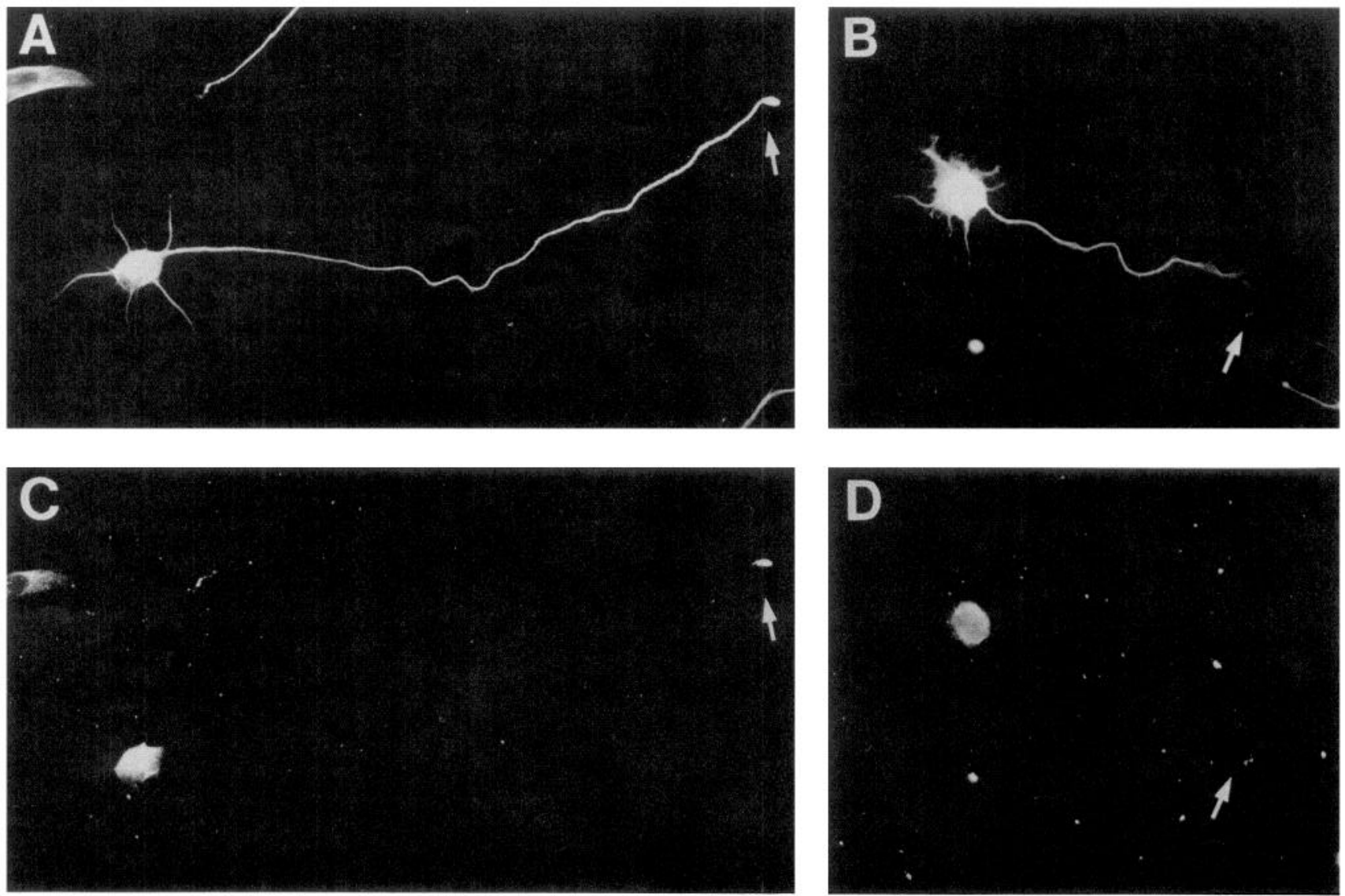

Figure 8. APP is confined to the cell body of cultured hippocampal neurons in the presence of kinesin heavy-chain antisense oligonucleotides after 1 DIV. $A$ and $C$ are a control cell treated with kinesin sense oligonucleotides and double labeled with tubulin antibody $(A)$ and the APP antibody C5 $(C)$. The arrow in $C$ shows the typical site of APP at the growth cone. $B$ and $D$ are a cell treated with kinesin antisense oligonucleotides and double labeled with tubulin antibody $(B)$ and the APP antibody C7. The arrows show the tip of the process with only trace labeling by C7. Scale bar, $20 \mu \mathrm{m}$.

tides as described previously (Ferreira et al., 1992). These antisense oligonucleotides are capable of suppressing kinesin heavychain expression and of retarding the movement of molecules associated with organelle-based rapid transport (Ferreira et al., 1992). One hour after plating the hippocampal neurons, kinesin heavy-chain antisense oligonucleotides were added to the medium and additional doses of the oligonucleotides were administered every $12 \mathrm{hr}$. At 24 and $48 \mathrm{hr}$ after plating the cells were fixed and double labeled for APP and tubulin (Fig. 8). Staining with the tubulin antibody demonstrated that the cells had developed processes, albeit shorter than control sense oligonucleotide-treated cultures; however, APP failed to enter the processes and was confined to the cell body. This appearance was very different from the normal growth cone localization of APP in hippocampal cultures at $24 \mathrm{hr}$. The inhibition of APP transport to the neurite tip suggested that its anterograde translocation is mediated by a kinesin-based motor.

\section{Discussion}

\section{Neuronal localization}

APP is detected most prominently in neurons, but its precise localization within neurons is not entirely clear from previous analyses of tissue sections. Dissociated neuronal cultures can sometimes reveal the localization of a protein when localization in tissue sections is problematic due to the very close apposition of neural and non-neural elements. An additional level of complexity in the analysis of neuronal localization is the very significant morphological changes that occur as a function of development. From the analysis of developing hippocampal cultures, it appears that APP is restricted to the advancing tip of the growth cone membrane. APP could be positioned at this site to serve a regulatory role in the control of neuronal growth. Contact is not the signal for redistribution into the axonal shaft since the more mature axonal pattern does not emerge until

Figure 7. Redistribution of late endosomes in hippocampal neurons following acidification of the medium. $A$ and $B$ are the same cell labeled with antibody C7 $(A)$ and Lucifer yellow $(B)$ after a 30 min incubation in Lucifer yellow and a 30 min chase. $C$ and $D$ are the same microscopic fields labeled with antibody $\mathrm{C} 7(C)$ and Lucifer yellow $(D)$ treated with Ringer's $\mathrm{pH} 6.90$ for 15 min following the chase. Considerably more abundant punctate labeling by the APP antibody is apparent in the processes $(C)$ that frequently colocalizes (arrows) with Lucifer yellow-labeled late endosomes $(D) . E$ and $F$ are the same cell labeled with the MAP2 antibody AP14 $(E)$ and with Lucifer yellow under the same conditions as $C$ and $D$. The arrows in $E$ correspond to the dots in $F$, demonstrating that the $\mathrm{pH}$ shift redistributes the late endosomes into axons as demonstrated by their failure to label with the MAP2 antibody. Scale bars, $20 \mu \mathrm{m}$. 
approximately 12-15 d after plating, whereas synapse formation begins at $5 \mathrm{~d}$ (Fletcher et al., 1991).

The correspondence between punctate synaptophysin staining and the presence of synapses by electron microscopy of hippocampal cultures was shown previously (Fletcher et al., 1991). APP did not colocalize with these synaptic sites in 30-d-old hippocampal cultures (Fig. 6); instead, it colocalized with vesicular appearing clusters of clathrin-immunoreactive structures (Fig. 5). Because the staining appeared vesicular, it is likely that the clathrin-immunoreactive structures represent membranebound organelles with assembled clathrin triskelions. Why these organelle-like structures cluster at nonsynaptic sites is unknown.

\section{Neuronal transport and sorting of $A P P$}

Because kinesin antisense oligonucleotides inhibited the anterograde transport of APP, some portion of the APP found in axons utilizes the motor protein kinesin for its anterograde translocation (Fig. 8). Although the hypothetical characteristics of an APP-transporting organelle must include specific targeting to the axon, this localization cannot arise simply by the segregation of the APP motor. Kinesin is present in both axons and dendrites in hippocampal neurons in culture (Ferreira et al., 1992). Hooking cargo to a minus-end-directed motor has been proposed as one way to exclude organelles, such as ribosomes, from the axon (Black and Baas, 1989), but the complementary problem of a mechanism for enriching delivery to the axon of organelles such as the synaptic vesicle is unclear. The identity of the organelle carrying APP is unknown. In developing neurites these organelles will likcly transit to the tip before their insertion into the distal membrane.

One hypothesis concerning the neuronal sorting of surface glycoproteins is that they follow pathways similar to those identified in polarized epithelial cells such as MDCK cells (Dotti and Simons, 1990). The glycoprotein product from the vesicular stomatitis virus sorts to the basolateral surface of MDCK cells, and the glycoprotein product of the avian influenza fowl plague virus sorts to the apical surface of MDCK cells. These same viral glycoproteins sort preferentially to the dendrite and the axon, respectively, of polarized hippocampal neurons (Dotti and Simons, 1990). APP is the first endogenous glycoprotein in neurons shown to follow one limb of this hypothesized sorting schema. Since some portion of apical sorting in MDCK cells occurs via transcytosis, an analogous mechanism may operate to sort APP to the axon, where it creates a specific modification of the axonal membrane.

Although the sorting of surface glycoproteins suggested an analogy between the apical surface of MDCK cells and the axon, the response of the late endosomes to acidification of the media suggested a closer resemblance of the axon to the basolateral surface. The $\mathrm{pH}$ shift in neurons resulted in the movement of late endosomes to the axon and in MDCK cells to the basolateral surface; in both of these regions microtubules are aligned with their plus ends distal (Heidemann et al., 1981; Bacallao et al., 1989). The axon as a specialized cellular domain may draw upon sorting mechanisms used by both the apical and basolateral systems in order to sort different categories of organelles and their constituent proteins.

\section{Mernbrane trafficking of APP in neurons}

The colocalization of APP with clathrin-reactive structures raises the possibility that APP internalization in neurons occurs via receptor-mediated endocytosis. The endocytosis of a variety of receptors is facilitated by clathrin-mediated internalization from either the plasma membrane or the trans-Golgi membrane (for review, see Pearse and Robinson, 1990). If APP can function as a receptor on the plasma membrane, its punctate staining observed in the neuronal culture system might serve as an assay to analyze ligand-mediated internalization.

Transport studies demonstrated that clathrin heavy and light chains move anterograde in the axon with a number of cytoskeletal proteins described as SCb or slow component $b$ (Garner and Lasek, 1981; Gower and Tytell, 1987). It is believed that clathrin moves anterograde unassembled, since if it were coating an organelle one would predict its presence in rapid axonal transport. When clathrin is associated with an organelle, as is suggested here, it is more likely moving in a retrograde direction.

Clathrin-coated vesicles route their contents to early endosomes from both the plasma membrane and the trans-Golgi. The presence of APP within early endosomes of neurons has not been directly demonstrated. The next site in the internalization process where it is possible to detect APP is in the late endosome positioned in the region of the neuronal cell body. The late endosome was identified here by reducing the $\mathrm{pH}$ of the culture medium to induce the redistribution of these organelles into processes (Fig. 7). While under basal conditions only a subset of the axons in culture have the punctate APP reactivity, the shift in the $\mathrm{pH}$ results in the punctate staining of nearly all axons. This observation suggests that relative to the pool of APP in clathrin-coated vesicles there is a larger pool in late endosomes. Among the various known molecules internalized via clathrin-coated vesicles, only a subset reach the late endosome. For instance, the low-density lipoprotein receptor gets recycled to the plasma membrane while only its ligand, the low-density lipoprotein, gets degraded in the lysosome (Goldstein et al., 1979). The epidermal growth factor (EGF) receptor, on the other hand, does get degraded in lysosomes along with EGF (Carpenter and Cohen, 1979). Like the EGF receptor, APP spans the membrane one time and has a cysteine-rich amino terminus; the secreted form of APP, protease nexin II, can form complexes with EGF-binding protein, a pro-EGF-processing serine esterase (reviewed in Monard, 1988). Unlike EGF, if APP does function as a receptor it does not transduce its signal by serving as a kinase. Nevertheless, the presence of APP in late endosomes suggests that in neurons most of the APP is degraded rather than cycled back to the plasma membrane since the late endosomal compartment contains very low amounts of recycled molecules (Geuze et al., 1983; Schmid et al., 1988).

Finally, perhaps there is some similarity between APP internalization and the way in which polymeric immunoglobulin $A$ is internalized on the basolateral surface of some epithelial cells. In this case a protein fragment is transcytosed to the apical domain and secreted (reviewed in Mostov and Simister, 1985). Indeed, there are cleaved forms of APP that are secreted and the segregation of glycoproteins to the axon may occur transcytotically (Dotti and Simons, 1990). It will be crucial to learn whether APP is present in its full-length form or as a fragment in the various neuronal compartments found here.

\section{References}

Bacallao R, Antony C, Dotti C, Karsenti E, Stelzer EHK, Simons K (1989) The subcellular organization of Madin-Darby canine kidney cells during the formation of a polarized epithelium. J Cell Biol 109: $2817-2832$.

Bahmanyar S, Higgins GA, Goldgaber D, Lewis DA, Morrison JH, Wilson MC, Shanker SK, Gajdusek DC (1988) Localization of am- 
yloid $\beta$ protein messenger RNA in brains from patients with Alzheimer's disease. Science 237:77-80.

Bartlett WP, Banker GA (1984) Electron microscopic studies of axonal and dendritic development by hippocampal neurons in culture. I. Cells which develop without intercellular contacts. J Neurosci 4:19441953.

Bendotti C, Forloni GL, Morgan RA, O'Hara BF, Oster-Granite ML, Reeves RH, Gearhart JD, Coyle JT (1988) Neuroanatomical localization and quantification of amyloid precursor protein mRNA by in situ hybridization in the brains of normal aneuploid and lesioned mice. Proc Natl Acad Sci USA 85:3628-3632.

Black MM, Baas P W (1989) The basis of polarity in neurons. Trends Ncurosci 12:211-214.

Bloom SW, Fields KL, Yen SH, Haver H, Schook W, Puszkin S (1980) Brain clathrin: immunofluorescent patterns in cultured cells and tissues. Proc Natl Acad Sci USA 77:5520-5524.

Bottenstein JE, Sato GH (1979) Growth of a rat neuroblastoma cell line in serum-free supplemented medium. Proc Natl Acad Sci USA 76:514-517.

Brodsky F (1985) Clathrin structure characterized with monoclonal antibodies. I. Analysis of multiple antigenic sites. J Cell Biol 101: 2047-2054.

Card JP, Meade RP, Davis LG (1988) Immunocytochemical localization of the precursor protein for $\beta$-amyloid in the rat central nervous system. Neuron 1:835-846.

Carpenter G, Cohen S (1979) Epidermal growth factor. Annu Rev Biochem 48:193-216.

Catterucia N, Willingale-Theune J, Bunke D, Prior R, Master CL, Crisanti A, Beyreuther K (1990) Ultrastructural localization of the putative precursors of the A4 amyloid protein associated with Alzheimer's disease. Am J Pathol 137:19-26.

Cohen ML, Golde TE, Usiak MF, Younkin LH, Younkin SG (1988) In situ hybridization of nucleus basalis neurons shows increased $\beta$-amyloid mRNA in Alzheimer disease. Proc Natl Acad Sci USA 85: $1227-1231$.

Dotti CG, Simons K (1990) Polarized sorting of viral glycoproteins to the axon and dendrites of hippocampal neurons in culture. Cell 62:63-72.

Estus S, Golde TE, Kunishita T, Blades D, Lowery D, Eisen M, Usiak M, Qu X, Tabira T, Greenberg BD, Younkin SG (1992) Potentially amyloidogenic, carboxyl-tcrminal derivatives of the amyloid protein precursor. Science 255:726-728.

Ferreira A, Niclas J, Vale RD, Banker G, Kosik KS (1992) Suppression of kinesin expression in cultured hippocampal neurons using antisense oligonucleotides. J Cell Biol 117:595-606.

Fletcher TL, Cameron P, DeCamilli P, Banker G (1991) The distribution of synapsin I and synaptophysin in hippocampal neurons developing in culture. $\mathrm{J}$ Neurosci 11:1617-1626.

Garner JA, Lasek RJ (1981) Clathrin is axonally transported as part of slow component b: the microfilament complex. J Cell Biol 88:172178.

Geuze HJ, Slot JW, Strous GJ, Lodish HF, Schwartz AL (1983) Intracellular site of asialoglycoprotein receptor-ligand uncoupling: double label immunoelectron microscopy during receptor mediated endocytosis. Cell 32:277-287.

Golde TE, Estus S, Younkin LH, Selkoe DJ, Younkin SG (1992) Processing of the amyloid precursor to potentially amyloidogenic derivatives. Science 255:728-730.

Goldstein JL, Anderson GW, Brown MS (1979) Coated pits, coated vesicles and receptor-mediated endocytosis. Nature 279:679-685.

Gower DJ, Tytell M (1987) Axonal transport of clathrin-associated proteins. Brain Res 407:1-8.
Griffiths G, Simons K (1986) The trans Golgi network: sorting at the exit site of the Golgi complex. Science 234:438-443.

Haass N, Koo EH, Mellon A, Hung AY, Selkoe DJ (1992) Targeting of cell-surface $\beta$-amyloid precursor protein to lysosomes: alternative processing into amyloid-bearing fragments. Nature 357:500-503.

Hass C, Hung A, Selkoe DJ (1991) Processing of $\beta$-amyloid precursor protein in microglia and astrocytes favors an internal localization over constitutive secretion. J Neurosci 11:3783-3793.

Heidemann SR, Landers JM, Hamborg MA (1981) Polarity orientation of axonal microtubules. J Cell Biol 91:661-665.

Heuser J (1989) Changes in lysosome shape and distribution correlated with changes in cytoplasmic pH. J Cell Biol 108:855-864.

Hughson E, Wandinger-Ness A, Gauscpohl H, Griffiths G, Simons K (1988) The cell biology of enveloped virus infection of epithelial tissues. In: Centenary symposium of the Pasteur Institute, The molecular biology of infectious diseases (Schwartz M, ed), pp 75-89. Paris: Elsevier.

Kang J, Lemaire HG, Unterbeck A, Salbaum JM, Masters CL, Grzeschik K-H, Multhaup G, Beyreuther K, Muller-Hill B (1987) The precursor of Alzheimer's disease amyloid A4 protein resembles a cellsurface receptor. Nature 325:733-736.

Koo EH, Sisodia SS, Archer DR, Martin LJ, Weidemann A, Beyreuther K, Fischer P, Masters CL, Price DL (1990) Precursor of amyloid protein in Alzheimer disease undergoes fast anterograde axonal transport. Proc Natl Acad Sci USA 87:1561-1565.

Kosik KS (1992) Alzheimer's disease from a cell biological perspective. Science 256:780-783.

Monard D (1988) Cell-derived proteases and protease inhibitors as regulators of neurite outgrowth. Trends Neurosci 11:541-544.

Mostov KE, Simister NE (1985) Transcytosis. Cell 43:389-390.

Parton RG, Dotti CG, Bacallao R, Kurtz I, Simons K, Prydz K (1991) $\mathrm{pH}$-induced microtubule-dependent redistribution of late endosomes in neuronal and epithelial cells. J Cell Biol 113:261-274.

Pearse BMF, Robinson MS (1990) Clathrin, adaptors, and sorting. Annu Rev Cell Biol 6:151-171.

Schmid SL, Fuchs R, Male P, Mellman I (1988) Two distinct subpopulations of endosomes involved in membrane recycling and transport to lysosomes. Cell 52:73-83.

Schubert W, Prior R, Weidemann A, Dircken H, Multhaup G, Masters CL, Beyreuther K (1991) Localization of Alzheimer beta-A4 amyloid prccursor protein at central and peripheral sites. Brain Res 563: 184-194.

Selkoe DJ, Berman-Podlisny M, Joachim CL, Vickers EA, Lee G, Fritz LC, Oldersdorf T (1988) $\beta$-Amyloid precursor protein of Alzheimer disease occurs as 110-135 kilodalton membrane-associated protein in neural and nonneural tissue. Proc Natl Acad Sci USA 85:73417345.

Shivers BD, Hilbich C, Multhaup G, Salbaum M, Beyreuther K, Seeburg $P$ (1988) Alzheimer's disease amyloidogenic glycoprotein: expression pattern in rat brain suggests a role in cell contact. EMBO J $7: 1365-1370$.

Van Nostrand WE, Cunningham DD (1987) Purification of protease nexin II from human fibroblasts. J Biol Chem 18:8508-8514.

Weidemann A, Konig G, Bunke D, Fischer P, Salbaum JM, Masters CL, Beyreuther K (1989) Identification, biogenesis, localization of precursors of Alzheimer's disease A4 amyloid protein. Cell 57:115126.

Wong DH, Ignatius MJ, Parosky G, Parham P, Trojanowski JQ, Brodsky FM (1990) Neuron-specific expression of high-molecular-weight clathrin light chain. J Neurosci 10:3025-3031. 